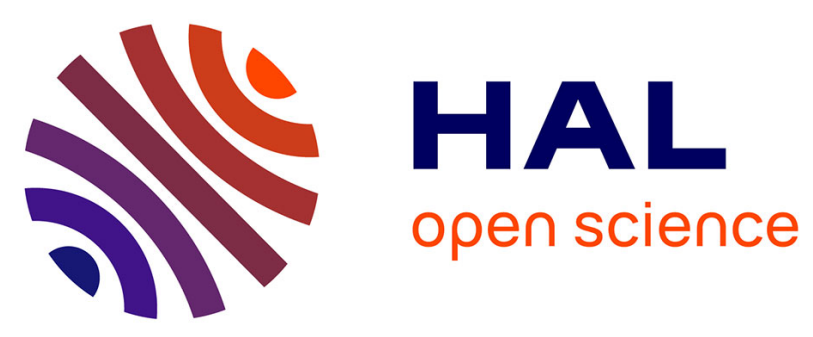

\title{
Quantifying the mediating effects of smoking and occupational exposures in the relation between education and lung cancer: the ICARE study
}

Gwenn Menvielle, Jeanna-Eve Franck, Loredana Radoï, Marie Sanchez, Joëlle Févotte, Anne-Valérie Guizard, Isabelle Stücker, Danièle Luce

\section{To cite this version:}

Gwenn Menvielle, Jeanna-Eve Franck, Loredana Radoï, Marie Sanchez, Joëlle Févotte, et al.. Quantifying the mediating effects of smoking and occupational exposures in the relation between education and lung cancer: the ICARE study. European Journal of Epidemiology, 2016, 31 (12), pp.1213-1221. 10.1007/s10654-016-0182-2 . hal-01360240

\section{HAL Id: hal-01360240 \\ https://hal.sorbonne-universite.fr/hal-01360240}

Submitted on 5 Sep 2016

HAL is a multi-disciplinary open access archive for the deposit and dissemination of scientific research documents, whether they are published or not. The documents may come from teaching and research institutions in France or abroad, or from public or private research centers.
L'archive ouverte pluridisciplinaire HAL, est destinée au dépôt et à la diffusion de documents scientifiques de niveau recherche, publiés ou non, émanant des établissements d'enseignement et de recherche français ou étrangers, des laboratoires publics ou privés. 
Quantifying the mediating effects of smoking and occupational exposures in the relation between education and lung cancer - the ICARE study

Menvielle Gwenn ${ }^{1}$, Franck Jeanna-eve ${ }^{1}$, Radoï Loredana ${ }^{23}$, Marie Sanchez ${ }^{24}$, Joëlle Févotte ${ }^{5}$, AnneValérie Guizard $^{6}$, Stücker Isabelle ${ }^{24}$, Luce Danièle ${ }^{78}$, Icare group

1 Sorbonne Universités, UPMC Univ Paris 06, INSERM, Institut Pierre Louis d'épidémiologie et de Santé Publique (IPLESP UMRS 1136), F75012, Paris, France

2 UMRS 1018, CESP Centre for Research in Epidemiology and Population Health, Environmental epidemiology of cancer, Villejuif, France

3 University of Paris Descartes, Paris

4 University of Paris Sud 11, Kremlin-Bicêtre, France

5 Unité Mixte de Recherche Épidémiologique et de Surveillance Transport Travail Environnement (UMRESTTE), Université Claude Bernard Lyon 1, 69373 Lyon, France

6 Calvados Cancer Registry, F-1400 Caen, France

7 Inserm U 1085 - IRSET, Pointe-à-Pitre, France

8 University of Rennes 1, Rennes, France

\section{Members of Icare Study Group}

Registre des cancers du Calvados, France (Anne-Valérie Guizard); Registre des cancers du Doubs, France (Arlette Danzon, Anne-Sophie Woronoff) ; Registre des cancers du Bas-Rhin, France (Michel Velten); Registre des cancers du Haut-Rhin, France (Antoine Buemi, Émilie Marrer); Registre des cancers de l'Hérault, France (Brigitte Tretarre); Registre des cancers de I'Isère, France (Marc Colonna, Patricia Delafosse); Registre des cancers de Loire-Atlantique-Vendée, France (Paolo Bercelli, Florence Molinie); Registre des cancers de la Manche, France (Simona Bara); Registre des cancers de la Somme, France (Benedicte Lapotre-Ledoux, Nicole Raverdy) ;

Inserm, Centre for research in Epidemiology and Population Health (CESP), U1018, Environmental epidemiology of cancer Team, Villejuif, France (Sylvie Cénée, Oumar Gaye, Florence Guida, Farida Lamkarkach, Loredana Radoï, Marie Sanchez, Isabelle Stücker);

Inserm Epidemiologic Cohorts Unit - UMS 011 INSERM-UVSQ, Villejuif, France (Matthieu Carton, Diane Cyr, Annie Schmaus)

Unité Mixte de Recherche Épidémiologique et de Surveillance Transport Travail Environnement (UMRESTTE), France (Joëlle Févotte, Corinne Pilorget)

Sorbonne Universités, UPMC Univ Paris 06, INSERM, Institut Pierre Louis d'épidémiologie et de Santé Publique (IPLESP UMRS 1136), Paris, France (Gwenn Menvielle)

Inserm U 1085 - IRSET, Pointe-à-Pitre, France (Danièle Luce)

\section{Key-words}

Lung cancer, incidence, France, men, smoking, occupational exposure

\section{Acknowledgements}


This work was supported by a grant from the French Agency for Food, Environmental and Occupational Health and Safety (ANSES) [grant number EST-2009/1/65] and by a grant from La Fondation ARC pour la Recherche sur le Cancer.

The ICARE study was funded by French National Research Agency (ANR); French National Cancer Institute (INCA); French Agency for Food, Environmental and Occupational Health and Safety (ANSES); French Institute for Public Health Surveillance (InVS); Fondation pour la Recherche Médicale (FRM); Fondation de France; La Fondation ARC pour la Recherche sur le Cancer; Ministry of Labour (Direction Générale du Travail); and Ministry of Health (Direction Générale de la Santé). 


\begin{abstract}
Background

Smoking only partly explains the higher lung cancer incidence observed among socially deprived people. Occupational exposures may account for part of these inequalities, but this issue has been little investigated. We investigated the extent to which smoking and occupational exposures to asbestos, silica and diesel motor exhaust mediated the association between education and lung cancer incidence in men.
\end{abstract}

\title{
Methods
}

We analyzed data from a large French population-based case-control study (1,976 lung cancers, 2,648 controls). Detailed information on lifelong tobacco consumption and occupational exposures to various carcinogens was collected. We conducted inverse probability-weighted marginal structural models.

Results

A strong association was observed between education and lung cancer. The indirect effect through smoking varied by educational level, with the strongest indirect effect observed for those with the lowest education (OR=1.34 (1.14-1.57)). The indirect effect through occupational exposures was substantial among men with primary ( $O R=1.22(1.15-1.30)$ for asbestos and silica) or vocational secondary education (OR=1.18 (1.12-1.25)). The contribution of smoking to educational differences in lung cancer incidence ranged from $22 \%(10-34)$ for men with primary education to $31 \%$ (-3-84) for men with a high school degree. The contribution of occupational exposures to asbestos and silica ranged from $15 \%$ (10-20) for men with a high school degree to $20 \%$ (13-28) for men with vocational secondary education.

\section{Conclusion}

Our results highlight the urgent need for public health policies that aim at decreasing exposure to carcinogens at work, in addition to tobacco control policies, if we want to reduce socioeconomic inequalities in the cancer field. 


\section{Introduction}

Large inequalities are consistently reported for male lung cancer incidence, with higher incidence rates among men with low socioeconomic position (SEP). Several studies have investigated the underlying mechanisms, the majority focusing on smoking. Most studies [1-5], although not all [6], found that smoking only partly accounted for these inequalities, including an analysis based on never smokers [7]. The possible role of other risk factors has almost never been investigated. However, there is some evidence that occupational exposures to carcinogens partly accounted for the higher lung cancer incidence rates among men with a low SEP. Occupational exposures were nevertheless assessed in a crude way through the number of jobs with possible exposure to carcinogens whatever the level of exposure in the job [8].

Studies investigating the role of risk factors as mediators in the association between SEP and lung cancer have based their conclusions on the comparison of statistical models with and without adjustment for the potential mediator, and on the estimation of the direct effect of SEP on lung cancer incidence once adjusting for the potential mediators. These are possibly biased methods for assessing mediation $[9,10]$. In addition, even in the absence of confounding, it is generally not possible to assess the magnitude of the indirect effect between SEP and lung cancer that is mediated by the risk factors investigated.

Recent developments in mediation analyses allow formally separating the direct and indirect effects between an exposure and an outcome while accounting for multiple mediators [11, 12]. These methods will improve our understanding of socioeconomic inequalities in lung cancer in two different ways. First, they will provide a precise estimation of the mediated effects through other risk factors in addition to smoking. Second, they will allow for different mediated effects for each socioeconomic category when using a measure of SEP with more than two categories. The aim of this analysis was to apply these newly developed methods to study the extent to which smoking and occupational exposures to asbestos, silica and diesel motor exhaust mediated the association between education and lung cancer incidence.

\section{Methods}

\section{Study population}

The ICARE study is a multi-center population-based case-control study conducted in France from 2001 through 2007 in 10 French "départements" (administrative areas) covered by a cancer register. 
The cases were all patients newly diagnosed with a primary, histologically confirmed malignant tumour of lung or head and neck cancers during the study period and who were aged 75 or less at diagnosis. The control group was selected from the general population of the same geographical areas (département) by random digit dialing, with frequency matching to all cases by sex and age. Additional stratification was used to achieve a distribution by socioeconomic status among the controls comparable to that of the general population. The study design has been described in details previously [13].

The present analysis was restricted to male lung cancer cases (International Classification of Diseases, $10^{\text {th }}$ Revision codes C33-34) and male controls. Indeed, studying inequalities in lung cancer risk would require a specific approach among women due to the contrasted and even reverse associations between education and smoking in different age groups among women. Among the 3865 male lung cancers identified as eligible from the cancer register files, 403 (10\%) could not be reached, 653 (17\%) were deceased and $197(5 \%)$ were too sick to be interviewed. Among the 2,612 who were contacted, 2,276 agreed to participate to the study (87\%). Of the 3,618 eligible male controls, 212 (6\%) could not be reached. Among the 3,406 who were contacted, 2,780 (82\%) agreed to participate to the study.

Subjects were interviewed face-to-face by trained interviewers, using a standardized questionnaire collecting detailed information about socio-demographic characteristics, lifetime tobacco consumption (type, period of consumption, frequency of consumption and quantities consumed for each period) and lifetime occupational history (covering all jobs held for at least 1 month).

Among the 2,276 lung cancers and 2,780 controls who participated to the study, some participants could not answer the whole questionnaire due to health problems. They filled in a restricted questionnaire instead that did not include information on education. We therefore conducted the analyses among subjects who answered the whole questionnaire $(2,074$ cases and 2,720 controls).

\section{Measure of smoking and occupational exposures}

Lifelong cigarette smoking was captured by the cumulative smoking index (CSI), which takes into account total duration of smoking, time since cessation and average number of cigarettes smoked per day [14]. A never smoker was considered having smoked less than 100 cigarettes in his lifetime. The CSI of never smokers is null. The properties of the CSI have been assessed and evaluated. In our data, the CSI varied linearly with lung cancer risk [15].

For each job, occupation and industrial activity were coded blind to the case-control status using respectively the International Standard Classification of Occupations 1968 (ISCO) and the French Nomenclature of Activities (NAF). Occupational exposure to asbestos and crystalline silica was then assessed using job-exposure matrices (JEM) specifically developed for France [16]. For each 
combination of an ISCO and a NAF code, the JEM assigned three indices of exposure: a probability of exposure, an intensity of exposure and a frequency of exposure. The indices were provided for different calendar periods between 1947 and 2007 to account for possible variations in exposure over time. For each subject, we derived from its entire occupational history a cumulative level of exposure to asbestos and crystalline silica obtained as the sum over all jobs of the product of the exposure intensity, probability, frequency and duration (using midpoints of each class).

Assessment of exposure to diesel motor exhaust (DME) (ever/never) was collected for each job and based on self-report. This information was missing for about $13 \%$ of all jobs, spread among $25 \%$ of men. We combined the ISCO code with the NAF code for each job. Missing values for exposure to DME were replaced by the modal category observed in the same ISCO-NAF combination among subjects with complete data. DME exposure was assessed from the questionnaire on a case-by-case basis when the modal category included less than $60 \%$ of the subjects. The association between lung cancer and ever exposure to DME was similar when using this variable and when restricting the analysis to complete case data [17].

\section{Analysis}

We investigated the role of three mediators in the association between education and lung cancer using the mediation methods recently proposed by Lange $[12,11]$. The syntax is provided elsewhere $[11,12]$. We adapted the method to account for the case-control design of our study following the strategy proposed by VanderWeele and Vansteelandt.[18] The mediation methods allow quantifying the natural direct and indirect effects of an exposure (here education) on an outcome (here lung cancer) while accounting for multiple mediators (here smoking and occupational exposures). Natural direct effect is defined as the change in lung cancer risk that would be observed if education could change (from high to lower) but leaving the mediators unchanged with the value observed among high educated. Natural indirect effect is defined as the change in lung cancer when education is kept fixed (high education) but the mediator is changed to the value it would take if education was changed (from high to lower). The natural indirect or mediated effect can be interpreted as the effect of education mediated through a specific factor.

The method is based on marginal structural models relying on several assumptions: $1 /$ there is no unmeasured confounding for the exposure-outcome, exposure-mediator and mediator-outcome relationship; 2 / there is no variable affected by the exposure that confounds any of the mediatoroutcome relationship; 3 / the mediators have no causal effect on each other. Education was included using the following categorization (primary, lower secondary or vocational upper secondary, high school, tertiary). Three successive models were performed. Age $(<=50,51-57,58-65$ and $>65)$ and residence area (ten départements) and the number of jobs held $(<3,3,4-5$ and $\geq 6)$ were introduced 
in all models as confounding categorical variables. In model 1 , we adjusted for smoking using the CSI as a continuous variable. In model 2 , we additionally adjusted for combined exposure to asbestos and silica as a categorical variable. Almost all men exposed to silica are also exposed to asbestos. Therefore, introducing asbestos and silica as two different mediators does not provide stable estimates because the two variables are not independent conditionally to education and the confounding factors. We first categorized exposure to asbestos and silica into none, low and high exposure. The cut-off was defined as the median of the cumulative index of exposure among exposed controls. The combined exposure to asbestos and silica variable was then created as follows: never exposed to asbestos nor silica, low exposure (no exposure to one carcinogen and low or high exposure to the other carcinogen; low exposure to both carcinogens) and high exposure (exposed to both carcinogens with high exposure to at least one). In model 3, we additionally adjusted for exposure to DME as a binary variable (ever/never).

Men with missing education were excluded from the analyses but coded as primary educated in sensitivity analyses $(n=84)$. These sensitivity analyses lead to similar results and are not presented. Data with other missing values were excluded $(n=86)$. A total of 98 cases and 72 controls were excluded from the analyses (4\%).

Sensitivity analyses were also conducted to assess the potential residual confounding by misclassification of smoking and occupational exposures. We randomly increased smoking consumption for $15 \%$ of ever smokers by selecting a higher smoking consumption value in the dataset. We increased occupational exposures to the immediately higher category among 5\% randomly selected men (see supplementary material).

All models performed include the calculation of stabilized weights to assess the direct and indirect effects. For more stable results we attributed to the $1 \%$ highest and $1 \%$ lowest weights the value of the $99^{\text {th }}$ and the first percentile. Confidence intervals $(\mathrm{Cl})$ were calculated using a bootstrap resampling method with 5000 replications. Analyses were conducted using SAS 9.4 and R version 3.1.2.

\section{Results}

Table 1 here 
The analysis was based on 1976 lung cancer cases and 2648 controls. The characteristics of the controls by educational level are presented in Table 1. Smoking consumption as well as occupational exposure to asbestos, silica and DME increased as education decreased. Smoking consumption increased regularly with decreasing education; occupational exposures, though, seemed to be highly concentrated among men with vocational secondary education or lower education. The total effect of educational level and the effect of each mediator on lung cancer are presented in Table 2. A gradient between education and lung cancer risk was reported. When compared with men with university degree, risk ranged from 1.62 (95\% $\mathrm{Cl}$ 1.28-2.04) among men with high school degree to 3.85 (3.18-4.66) among primary educated. All mediators were associated with lung cancer risk. The association with DME was nevertheless modest as expected.

Tables 2 and 3 here

Natural direct and indirect effects conditional on confounders are presented in Table 3. In the model including all mediators, the effect mediated through smoking (or indirect effect of education through smoking) varied by educational level with the strongest indirect effect observed for those with primary education when compared with tertiary educated $(O R=1.35$ (1.15-1.58)). It can be interpreted as follows: a higher smoking consumption among men with primary education account for a $35 \%$ higher lung cancer risk in this group when compared with men with tertiary education. The indirect effect through exposure to asbestos and silica was lower but substantial among men with primary education (OR=1.23 (1.15-1.31)) or with vocational secondary education (OR=1.19 (1.121.25)). A small effect mediated through $D M E$ was observed ( $O R=1.03$ (1.00-1.07) among men with primary education). When all mediators were accounted for, the direct effect of education on lung cancer remained substantial among men with up to vocational secondary education when compared with tertiary education. Among men with a high school degree, the direct effect of education became non-significant although still elevated when exposure to asbestos and silica was introduced in the model.

The proportion of the total effect of educational level mediated by the mediators on the log odds scale is presented in table 3 . When all mediators are accounted for simultaneously, smoking accounted for a smaller part of the effect risk for primary educated men (22\% (10-34)) than for the two other educational groups (28\% (13-46) for men with vocational secondary education and 31\% (3-84) for men with a high school degree). The contribution of occupational exposures to asbestos and silica to the excess lung cancer risk was largest for men with vocational secondary education (20\% (13-28)) and smallest for men with a high school degree (12\% (4-27)). 


\section{Discussion}

Using recently developed methods, our analysis provides new insights into mediation and the pathways between education and lung cancer. We estimated the effect mediated through smoking and occupational exposures in three educational groups, instead of only contrasting low to high education. Our findings suggest that the mediation mechanisms differ by education level. The indirect effect through smoking was stronger among the lowest educated men due to longer and heavier consumption in this group $[19,20]$, but still substantial for men with high school degree. The indirect effect through occupational exposures was large and similar among men with primary or vocational secondary education but was modest among men with a high school degree when compared with tertiary educated. Mostly manual jobs lead to occupational exposures to carcinogens and in France these jobs are concentrated among men with primary or vocational secondary education.

In our data, smoking accounted for a substantial part of educational differences in lung cancer although smaller than what is reported in the literature [1-5]. Educational differences in smoking among the French male population were small among men born before $1955[19,21]$ and smaller than those observed in many other countries [22], which is likely to explain this finding. Finally, the contribution of smoking to educational differences in lung cancer varied by educational level and was the largest for men with a high school degree. This counterintuitive result is the consequence of a small indirect effect through smoking when compared to the total effect of education on lung cancer incidence especially among the lowest educated. Educational differences in smoking have dramatically increased among younger male cohorts in France $[23,21]$; therefore the indirect effect through smoking and the contribution of smoking to educational differences in lung cancer incidence are likely to increase in the coming years.

The available literature, although based on very few studies suffering from limited information about occupational exposures [24, 25], suggested a role of occupational exposures in social inequalities in lung cancer incidence. Our study is the first to provide a detailed quantification of the contribution of occupational exposures to educational differences in lung cancer incidence and confirms the substantial contribution of occupational exposures to these inequalities. In our data, among men with less than a high school degree, this contribution was similar to that of smoking.

Several hypotheses could explain the remaining inequalities among the lowest educated. First, we cannot rule out residual confounding by smoking. This would occur in all educational groups but may 
be larger among the lowest educated due to longer and heavier consumptions $[19,20]$. Second, although we already showed a substantial contribution of occupational exposures to educational differences in lung cancer incidence, we may have underestimated this contribution as we did not account for some lung cancer carcinogens (e.g. chromium VI or nickel) because of no data availability. We nevertheless adjusted for the three carcinogens with the highest number of attributable lung cancer cases [26]. Finally, other risk factors such as poor diet [27] or physical inactivity [28], more prevalent among the lowest educated [29, 30], may also account for part of the remaining direct effect between education and lung cancer. In addition, air pollution is associated with an increased lung cancer risk [31, 32]. However, the association between lower SEP and air pollution, although observed in some settings [33], is not clear in France where it differs by geographical context.[34]

The ICARE study is a large case-control study on lung cancer and occupational risk factors. The participation rate was over $80 \%$ in cases and controls. Recall bias is a well-known weakness of casecontrol studies. Therefore we paid special attention to data collection. Detailed information was collected by trained interviewers during face-to-face interviews, with a standardized questionnaire, and in a similar manner among cases and controls.

We collected detailed information on lifetime tobacco consumption, with information on the different types and quantity consumed for the different consumption periods. However, we did not account for differences in the type of tobacco smoked (brown or blond, use of filter) in our measure of lifelong smoking. Although around $26 \%$ of men (age standardized figure) reported being never smokers in France in 2005 [20], a proportion close to our figures (28\%), we cannot rule out an underestimation of tobacco consumption, which may differ by education [35], and therefore possibly bias our estimates for smoking.

Occupational exposures were assessed thanks to the lifetime job history. Self-reported occupational history is usually considered as reliable [36]. Occupations were coded blind to the case-control status. Occupational exposure to asbestos and silica was assessed through specific JEMs developed for France. A JEM generates only non-differential misclassification which could result in an underestimation of the association between the carcinogens and lung cancer and an underestimation of the indirect effect through occupational exposures. Previous studies have validated these JEMs $[37,38]$. Lifetime prevalence of asbestos and silica exposure among our controls was close to that estimated in France [16]. Therefore, we believe that our data for occupational exposure to asbestos and silica are of good quality. Regarding exposure to DME, we 
cannot exclude a recall bias. However, $26.2 \%$ of our controls reported at least one job with DME exposure, a proportion close to that found in an Italian study [39].

Sensitivity analyses suggested that possible misclassification of smoking and occupational exposures did not account for our findings. Although the indirect effects were smaller in the sensitivity analyses than in our main analyses, the main conclusions did not change. For instance, the indirect effect among primary educated men for smoking decreased from 1.35 (1.15-1.58) to 1.27 (1.09-1.47). In addition, the indirect effects for occupational exposures were not affected by smoking misclassification (see supplementary material).

The methods that we used rely on several assumptions. We checked these assumptions by testing exposure-mediator interaction on outcome and independence between mediators conditional on exposure and confounders. In addition the stability of our estimates for the indirect effects of each mediator when successively introduced in the models suggests that the three mediators investigated represent distinct non-intertwined causal pathways and that our models are valid. The methods that we used do not always lead to stable estimates when using continuous mediator. Nevertheless, considering the CSI as a categorical or a continuous variable led to almost identical results. We therefore kept the CSI as a continuous variable in order not to reduce the statistical power by categorization and to minimise the number of variables in our models. Finally, a lack of statistical power cannot be ruled out for men with a high school degree and may account for the results in this group, namely the non significant direct effect after accounting for smoking and the proportion explained by the direct and the indirect effects lower than $100 \%$ when accounting for occupational exposure.

In conclusion, our study provides additional evidence that smoking does not account for all social inequalities in lung cancer risk. Our analyses stress the importance of occupational exposures in the genesis of social inequalities in lung cancer. This risk factor is often overlooked in social epidemiology where most studies concentrate on behavioural risk factors. Noteworthy, among men with up to vocational secondary education, the indirect effect through occupational exposures to asbestos, silica and DME was only slightly smaller than the indirect effect through smoking. Therefore tackling only smoking will leave large inequalities among a significant part of the French male population. Our results highlight the need for policy efforts to reduce both tobacco consumption and occupational exposures among men. There is now a substantial body of literature evaluating the effect of tobacco control policies on reducing social inequalities in smoking [40-42]. Most strategies, including those implemented in France during the last decade, focused on modifying individual behaviors. However, 
the observed trends in smoking rates by SEP in France [19] as elsewhere [43] showed that such strategies largely failed to reduce inequalities in smoking. Policies should be implemented in a more comprehensive framework and address the social conditions and determinants where behaviors are rooted [44]. Given the dramatic increase in educational differences in smoking in France among younger generations, such policies are urgently needed to limit the burden of smoking in socioeconomic inequalities in health in the future. If progress have been achieved towards the reduction of workers exposure to carcinogens, continued efforts are needed. Active policies aiming at decreasing occupational exposures at workplace through legislation and the use of protection devices for workers would be efficient to reduce inequalities and would save a substantial number of lung cancer cases in particular among low educated men. 
Table 1: Characteristics of controls according to educational level. Icare 2002-2007 men.

\begin{tabular}{|c|c|c|c|c|c|}
\hline & $\begin{array}{l}\text { No diploma } \\
\text { or primary }\end{array}$ & $\begin{array}{l}\text { Vocational } \\
\text { secondary }\end{array}$ & High school & Tertiary & Pvalue \\
\hline \multicolumn{6}{|l|}{ Cumulative lifetime cigarette consumption (CSI) } \\
\hline Never smoker & $151(28.4)$ & $291(27.2)$ & $85(27.8)$ & $246(33.3)$ & 0.04 \\
\hline Mean (SD) among ever smoker & $1.45(0.71)$ & $1.29(0.69)$ & $1.22(0.72)$ & $1.09(0.72)$ & $<0.001$ \\
\hline Combined exposure to asbestos and silica ${ }^{a}$ & & & & & $<0.001$ \\
\hline Never exposed & $144(27.1)$ & $301(28.1)$ & $160(52.3)$ & $473(64.0)$ & \\
\hline Low & $246(46.2)$ & $503(47.0)$ & $116(37.9)$ & $230(31.1)$ & \\
\hline High & $142(26.7)$ & $267(24.9)$ & $30(9.8)$ & $36(4.9)$ & \\
\hline Diesel motor exhaust (DME) exposure & & & & & $<0.001$ \\
\hline Never & $361(67.9)$ & $733(68.4)$ & $228(74.5)$ & $633(85.7)$ & \\
\hline Ever & $171(32.1)$ & $338(31.6)$ & $78(25.5)$ & $106(14.3)$ & \\
\hline
\end{tabular}

Data are presented as $\mathrm{n}(\%)$ or mean (standard deviation, SD)

${ }^{\mathrm{a}}$ low exposure $=$ no exposure to asbestos or silica and low or high exposure to silica or asbestos; or low exposure to asbestos and silica

high exposure $=$ exposed to asbestos and silica with high exposure to asbestos and/or silica

Cumulative level of asbestos (fibers/mL.year): Low : $<0.27$ / High : $\geq 0.27$

Cumulative level of silica (mg/m3.year) : Low : $<0.14$ / High : $\geq 0.14$ 
Table 2: Total effect of educational level and effects of each mediator on lung cancer risk. Icare 2002-

2007 men

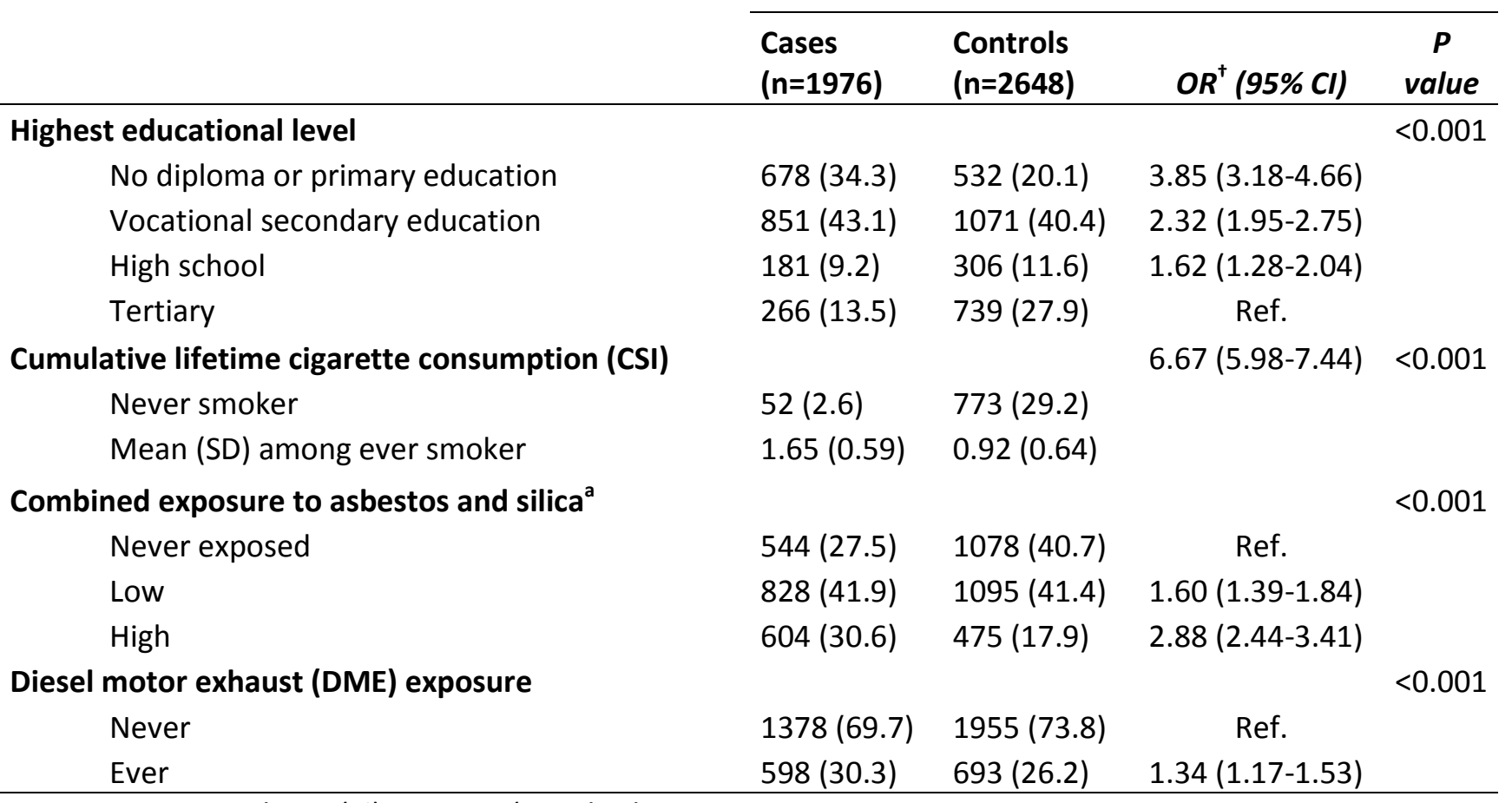

Data are presented as $\mathrm{n}(\%)$ or mean (standard

deviation, SD)

${ }^{\dagger}$ Adjusted for age and department and number of jobs

${ }^{a}$ low exposure $=$ no exposure to asbestos or silica and low or high exposure to silica or asbestos; or low exposure to asbestos and silica

high exposure $=$ exposed to asbestos and silica with high exposure to asbestos and/or silica

Cumulative level of asbestos (fibers/mL.year): Low : $<0.27$ / High : $\geq 0.27$

Cumulative level of silica (mg/m3.year) : Low : $<0.14$ / High : $\geq 0.14$ 
Table 3: Direct and mediated effects (OR and 95\% confidence intervals) of educational level on lung cancer for each mediator derived from the marginal structural models including multiple mediators. Icare 2002-2007 men.

\begin{tabular}{|c|c|c|c|c|c|}
\hline $\begin{array}{l}\text { Primary -> } \\
\text { Tertiary }\end{array}$ & Proportion (\%) & $\begin{array}{c}\text { Vocational secondary - } \\
>\text { Tertiary }\end{array}$ & Proportion (\%) & $\begin{array}{c}\text { High school -> } \\
\text { Tertiary }\end{array}$ & Proportion (\%) \\
\hline
\end{tabular}

\begin{tabular}{|c|c|c|c|c|c|c|}
\hline \multicolumn{7}{|l|}{ Smoking as mediator } \\
\hline \multicolumn{7}{|c|}{ Smoking and combined exposure to asbestos and silica as mediators } \\
\hline Indirect effect through CSI & $1.34(1.14-1.57)$ & $22(10-34)$ & $1.27(1.12-1.45)$ & $29(13-46)$ & $1.16(0.98-1.38)$ & $31(-3-84)$ \\
\hline $\begin{array}{l}\text { Indirect effect through } \\
\text { asbestos and silica }\end{array}$ & $1.23(1.15-1.31)$ & $15(10-20)$ & $1.19(1.12-1.25)$ & $20(13-29)$ & $1.06(1.03-1.11)$ & $13(5-29)$ \\
\hline Indirect effect through CSI & $1.34(1.14-1.57)$ & $22(10-34)$ & $1.27(1.12-1.44)$ & $28(13-46)$ & $1.16(0.98-1.38)$ & $31(-3-84)$ \\
\hline $\begin{array}{l}\text { Indirect effect through } \\
\text { asbestos and silica }\end{array}$ & $1.22(1.15-1.30)$ & $15(10-20)$ & $1.18(1.12-1.25)$ & $20(13-28)$ & $1.06(1.02-1.10)$ & $12(4-27)$ \\
\hline Indirect effect through DME & $1.03(1.00-1.07)$ & $2(0-5)$ & $1.02(1.00-1.05)$ & $3(0-6)$ & $1.02(1.00-1.04)$ & $3(0-11)$ \\
\hline
\end{tabular}

CSI: Comprehensive smoking index; DME: diesel motor exhaust

${ }^{\text {a }}$ Proportion $=\ln \left(O R_{\text {indirect }}\right) / \ln \left(O R_{\text {total }}\right)$, with $O R_{\text {total }}$ as shown in table 2

Corresponds to the proportion of the total effect of education on lung cancer risk mediated by the mediator (when compared with tertiary educated) (on the log odds scale) 
1. Bennett VA, Davies EA, Jack RH, Mak V, Moller H. Histological subtype of lung cancer in relation to socio-economic deprivation in South East England. BMC Cancer. 2008;8:139.

2. Ekberg-Aronsson M, Nilsson PM, Nilsson JA, Pehrsson K, Lofdahl CG. Socio-economic status and lung cancer risk including histologic subtyping--a longitudinal study. Lung Cancer. 2006;51(1):21-9. doi:10.1016/j.lungcan.2005.08.014.

3. Hart CL, Hole DJ, Gillis CR, Smith GD, Watt GC, Hawthorne VM. Social class differences in lung cancer mortality: risk factor explanations using two Scottish cohort studies. Int J Epidemiol. 2001;30(2):268-74.

4. Mao $Y$, Hu J, Ugnat AM, Semenciw R, Fincham S. Socioeconomic status and lung cancer risk in Canada. Int J Epidemiol. 2001;30(4):809-17.

5. Menvielle $G$, Boshuizen $H$, Kunst $A E$, Dalton SO, Vineis $P$, Bergmann MM, Hermann S, Ferrari $P$, Raaschou-Nielsen O, Tjonneland A, Kaaks R, Linseisen J, Kosti M, Trichopoulou A, Dilis V, Palli D, Krogh V, Panico S, Tumino R, Buchner FL, van Gils CH, Peeters PH, Braaten T, Gram IT, Lund E, Rodriguez L, Agudo A, Sanchez MJ, Tormo MJ, Ardanaz E, Manjer J, Wirfalt E, Hallmans G, Rasmuson T, Bingham S, Khaw KT, Allen N, Key T, Boffetta P, Duell EJ, Slimani N, Gallo V, Riboli E, Bueno-deMesquita HB. The role of smoking and diet in explaining educational inequalities in lung cancer incidence. J Natl Cancer Inst. 2009;101(5):321-30.

6. Nkosi TM, Parent ME, Siemiatycki J, Rousseau MC. Socioeconomic position and lung cancer risk: how important is the modeling of smoking? Epidemiology. 2012;23(3):377-85. doi:10.1097/EDE.0b013e31824d0548.

7. Menvielle G, Truong T, Jellouli F, Stücker I, Brenner H, Field J, Hosgood H, Lan Q, Landi M, Hung R, Lazarus P, McLaughlin J, Morgenstern H, Muscat J, Ruano-Ravina A, Schwartz A, Seow A, Spitz M, Tardon A, Zhang Z, Luce D. Letter to the editor. Education and lung cancer among never smokers. Epidemiology. 2014;25(6):934-5.

8. Menvielle $G$, Kunst $A E$, van Gils $C H$, Peeters $P H$, Boshuizen $H$, Overvad $K$, Olsen $A$, Tjonneland $A$, Hermann S, Kaaks R, Bergmann MM, Illner AK, Lagiou P, Trichopoulos D, Trichopoulou A, Palli D, Berrino F, Mattiello A, Tumino R, Sacerdote C, May A, Monninkhof E, Braaten T, Lund E, Quiros JR, Duell EJ, Sanchez MJ, Navarro C, Ardanaz E, Borgquist S, Manjer J, Khaw KT, Allen NE, Reeves GK, Chajes V, Rinaldi S, Slimani N, Gallo V, Vineis P, Riboli E, Bueno-de-Mesquita HB. The contribution of risk factors to the higher incidence of invasive and in situ breast cancers in women with higher levels of education in the European prospective investigation into cancer and nutrition. Am J Epidemiol. 2011;173(1):26-37.

9. Jiang Z, VanderWeele TJ. When is the difference method conservative for assessing mediation? Am J Epidemiol. 2015;182(2):105-8. doi:10.1093/aje/kwv059.

10. Hafeman DM. "Proportion explained": a causal interpretation for standard measures of indirect effect? Am J Epidemiol. 2009;170(11):1443-8.

11. Lange $T$, Rasmussen $M$, Thygesen LC. Assessing natural direct and indirect effects through multiple pathways. Am J Epidemiol. 2014;179(4):513-8. doi:10.1093/aje/kwt270.

12. Lange $T$, Vansteelandt $S$, Bekaert $M$. A simple unified approach for estimating natural direct and indirect effects. Am J Epidemiol. 2012;176(3):190-5. doi:10.1093/aje/kwr525.

13. Luce D, Stucker I. Investigation of occupational and environmental causes of respiratory cancers (ICARE): a multicenter, population-based case-control study in France. BMC Public Health. 2011;11:928. doi:10.1186/1471-2458-11-928.

14. Leffondre $\mathrm{K}$, Abrahamowicz $M$, Xiao $\mathrm{Y}$, Siemiatycki J. Modelling smoking history using a comprehensive smoking index: application to lung cancer. Stat Med. 2006;25(24):4132-46.

15. Papadopoulos A, Guida F, Leffondre K, Cenee S, Cyr D, Schmaus A, Radoi L, Paget-Bailly S, Carton M, Menvielle G, Woronoff AS, Tretarre B, Luce D, Stucker I. Heavy smoking and lung cancer: are women at higher risk? Result of the ICARE study. $\mathrm{Br} J$ Cancer. 2014;110(5):1385-91. doi:10.1038/bjc.2013.821. 
16. Févotte J, Dananché B, Delabre L, Ducamp S, Garras L, Houot M, Luce D, Orlowski E, Pilorget C, Lacourt A, Brochard P, Goldberg M, Imbernon E. Matgene: a program to develop job-exposure matrices in the general population in France. Ann Occup Hyg. 2011;55:865-78.

17. Matrat $M$, Guida $F$, Kromhout $H$, Peters $S$, Vermeulen R, Cénée $S$, Févotte J, Carton $M, C y r D$, Menvielle G, Paget-Bailly S, Radoï L, Schmaus A, Bara S, Velten M, Luce D, Stücker I, The ICARE study group. Occupational exposure to diesel motor exhaust and lung cancer: A dose-response relationship hidden by asbestos exposure adjustment? The ICARE study. J Cancer Epidemiol. 2015;879302. doi:10.1155/2015/879302.

18. Vanderweele TJ, Vansteelandt $\mathrm{S}$. Odds ratios for mediation analysis for a dichotomous outcome. Am J Epidemiol. 2010;172(12):1339-48. doi:10.1093/aje/kwq332.

19. Bricard D, Jusot F, Beck F, Khlat $M$, Legleye $S$. Educational inequalities in smoking over the life cycle: an analysis by cohort and gender. Int J Public Health. 2015. doi:10.1007/s00038-015-0731-6.

20. Peretti-Watel $P$, Beck F, Wilquin J. Les Français et la cigarette en 2005 : un divorce pas encore consommé. In: Beck F, Guilbert $P$, Gautier A, editors. Baromètre santé 2005. Attitudes et comportement de santé. Saint-Denis: INPES; 2007. p. 77-110.

21. Legleye $S$, Khlat $M$, Beck $F$, Peretti-Watel $P$. Widening inequalities in smoking initiation and cessation patterns: a cohort and gender analysis in France. Drug Alcohol Depend. 2011;117(2-3):23341. doi:S0376-8716(11)00088-3 [pii]

10.1016/j.drugalcdep.2011.02.004.

22. Cavelaars AE, Kunst AE, Mackenbach JP. Socioeconomic differences in risk factors for morbidity and mortality in the European Community: an international comparison. Journal of Health Psychology. 1997;2:353-72.

23. Bricard $D$, Jusot $F$, Beck $F$, Khlat $M$, Legleye $S$. Educational inequalities in smoking over the life cycle: an analysis by cohort and gender. Int J Public Health. 2016;61(1):101-9. doi:10.1007/s00038015-0731-6.

24. Menvielle $G$, Boshuizen $H$, Kunst AE, Vineis $P$, Dalton SO, Bergmann MM, Hermann $S$, Veglia $F$, Ferrari $P$, Overvad K, Raaschou-Nielsen $O$, Tjonneland A, Kaaks R, Linseisen J, Palli D, Krogh V, Tumino R, Rodriguez L, Agudo A, Sanchez MJ, Arozena JM, Cirera L, Ardanaz E, Bingham S, Khaw KT, Boffetta $P$, Duell E, Slimani N, Gallo V, Riboli E, Bueno-de-Mesquita HB. Occupational exposures contribute to educational inequalities in lung cancer incidence among men: Evidence from the EPIC prospective cohort study. Int J Cancer. 2010;126(8):1928-35.

25. van Loon AJ, Goldbohm RA, Kant IJ, Swaen GM, Kremer AM, van den Brandt PA. Socioeconomic status and lung cancer incidence in men in The Netherlands: is there a role for occupational exposure? J Epidemiol Community Health. 1997;51(1):24-9.

26. Brown T, Darnton A, Fortunato L, Rushton L. Occupational cancer in Britain. Respiratory cancer sites: larynx, lung and mesothelioma. $\mathrm{Br} J$ Cancer. 2012;107 Suppl 1:S56-70. doi:10.1038/bjc.2012.119.

27. Skuladottir H, Tjoenneland A, Overvad K, Stripp C, Christensen J, Raaschou-Nielsen O, Olsen JH. Does insufficient adjustment for smoking explain the preventive effects of fruit and vegetables on lung cancer? Lung Cancer. 2004;45(1):1-10.

28. Steindorf K, Friedenreich C, Linseisen J, Rohrmann S, Rundle A, Veglia F, Vineis P, Johnsen NF, Tjonneland A, Overvad K, Raaschou-Nielsen O, Clavel-Chapelon F, Boutron-Ruault MC, Schulz M, Boeing H, Trichopoulou A, Kalapothaki V, Koliva M, Krogh V, Palli D, Tumino R, Panico S, Monninkhof E, Peeters PH, Boshuizen HC, Bueno-de-Mesquita HB, Chirlaque MD, Agudo A, Larranaga N, Quiros JR, Martinez C, Barricarte A, Janzon L, Berglund G, Bingham S, Khaw KT, Key TJ, Norat T, Jenab M, Cust A, Riboli E. Physical activity and lung cancer risk in the European Prospective Investigation into Cancer and Nutrition Cohort. Int J Cancer. 2006;119(10):2389-97.

29. Malon A, Deschamps V, Salanave B, Vernay M, Szego E, Estaquio C, Kesse-Guyot E, Hercberg S, Castetbon K. Compliance with French nutrition and health program recommendations is strongly associated with socioeconomic characteristics in the general adult population. J Am Diet Assoc. 2010;110(6):848-56. doi:10.1016/j.jada.2010.03.027. 
30. Menai M, Charreire H, Feuillet T, Salze P, Weber C, Enaux C, Andreeva VA, Hercberg S, Nazare JA, Perchoux C, Simon C, Oppert JM. Walking and cycling for commuting, leisure and errands: relations with individual characteristics and leisure-time physical activity in a cross-sectional survey (the ACTICites project). Int J Behav Nutr Phys Act. 2015;12:150. doi:10.1186/s12966-015-0310-5.

31. Raaschou-Nielsen O, Andersen ZJ, Beelen R, Samoli E, Stafoggia M, Weinmayr G, Hoffmann B, Fischer P, Nieuwenhuijsen MJ, Brunekreef B, Xun WW, Katsouyanni K, Dimakopoulou K, Sommar J, Forsberg B, Modig L, Oudin A, Oftedal B, Schwarze PE, Nafstad P, De Faire U, Pedersen NL, Ostenson CG, Fratiglioni L, Penell J, Korek M, Pershagen G, Eriksen KT, Sorensen M, Tjonneland A, Ellermann T, Eeftens M, Peeters PH, Meliefste K, Wang M, Bueno-de-Mesquita B, Key TJ, de Hoogh K, Concin H, Nagel G, Vilier A, Grioni S, Krogh V, Tsai MY, Ricceri F, Sacerdote C, Galassi C, Migliore E, Ranzi A, Cesaroni G, Badaloni C, Forastiere F, Tamayo I, Amiano P, Dorronsoro M, Trichopoulou A, Bamia C, Vineis $P$, Hoek $G$. Air pollution and lung cancer incidence in 17 European cohorts: prospective analyses from the European Study of Cohorts for Air Pollution Effects (ESCAPE). Lancet Oncol. 2013;14(9):813-22. doi:10.1016/s1470-2045(13)70279-1.

32. Vineis P, Hoek G, Krzyzanowski M, Vigna-Taglianti F, Veglia F, Airoldi L, Overvad K, RaaschouNielsen O, Clavel-Chapelon F, Linseisen J, Boeing H, Trichopoulou A, Palli D, Krogh V, Tumino R, Panico S, Bueno-De-Mesquita HB, Peeters PH, Lund EE, Agudo A, Martinez C, Dorronsoro M, Barricarte A, Cirera L, Quiros JR, Berglund G, Manjer J, Forsberg B, Day NE, Key TJ, Kaaks R, Saracci R, Riboli E. Lung cancers attributable to environmental tobacco smoke and air pollution in non-smokers in different European countries: a prospective study. Environ Health. 2007;6:7.

33. Naess O, Piro FN, Nafstad P, Smith GD, Leyland AH. Air pollution, social deprivation, and mortality: a multilevel cohort study. Epidemiology. 2007;18(6):686-94. doi:10.1097/EDE.0b013e3181567d14.

34. Padilla CM, Kihal-Talantikite W, Vieira VM, Rossello P, Le Nir G, Zmirou-Navier D, Deguen S. Air quality and social deprivation in four French metropolitan areas--a localized spatio-temporal environmental inequality analysis. Environ Res. 2014;134:315-24. doi:10.1016/j.envres.2014.07.017.

35. Huerta M, Chodick G, Balicer RD, Davidovitch N, Grotto I. Reliability of self-reported smoking history and age at initial tobacco use. Prev Med. 2005;41(2):646-50. doi:10.1016/j.ypmed.2005.01.011.

36. Blair A, Stewart P, Lubin JH, Forastiere F. Methodological issues regarding confounding and exposure misclassification in epidemiological studies of occupational exposures. Am J Ind Med. 2007;50(3):199-207. doi:10.1002/ajim.20281.

37. Guida F, Paget-Bailly S, Lamkarkach F, Gaye O, Menvielle G, Papadopoulos A, Matrat M, Févotte J, Cenée S, Cyr D, Schmaus A, Carton M, Radoï L, Lapôtre-Ledoux B, Molinié F, Luce D, Stücker I. Risk of lung cancer associated with occupational exposure to mineral wools: Updating knowledge from a French population-based case-control study, the ICARE study. J Occup Environ Med. 2013;55(7):78695.

38. Lacourt A, Leffondre K, Gramond C, Ducamp S, Rolland P, Gilg Soit Ilg A, Houot M, Imbernon E, Fevotte J, Goldberg M, Brochard P. Temporal patterns of occupational asbestos exposure and risk of pleural mesothelioma. Eur Respir J. 2012;39(6):1304-12. doi:10.1183/09031936.00005111.

39. Richiardi L, Mirabelli D, Calisti R, Ottino A, Ferrando A, Boffetta P, Merletti F. Occupational exposure to diesel exhausts and risk for lung cancer in a population-based case-control study in Italy. Ann Oncol. 2006;17(12):1842-7. doi:10.1093/annonc/mdl307.

40. Thomas S, Fayter D, Misso K, Ogilvie D, Petticrew M, Sowden A, Whitehead M, Worthy G. Population tobacco control interventions and their effects on social inequalities in smoking: systematic review. Tob Control. 2008;17(4):230-7.

41. Schaap MM, Kunst AE, Leinsalu M, Regidor E, Ekholm O, Dzurova D, Helmert U, Klumbiene J, Santana P, Mackenbach JP. Effect of nationwide tobacco control policies on smoking cessation in high and low educated groups in 18 European countries. Tob Control. 2008;17(4):248-55.

42. Breton E, Sherlaw w. Examining tobacco control strategies and aims through a social justice lens: an application of Sen's capabilities approach. Public Health Ethics. 2011;4(2):149-59. 
43. Giskes K, Kunst AE, Benach J, Borrell C, Costa G, Dahl E, Dalstra JA, Federico B, Helmert U, Judge K, Lahelma E, Moussa K, Ostergren PO, Platt S, Prattala R, Rasmussen NK, Mackenbach JP. Trends in smoking behaviour between 1985 and 2000 in nine European countries by education. J Epidemiol Community Health. 2005;59(5):395-401. doi:10.1136/jech.2004.025684.

44. Commission on social determinants of health (CSDH). Closing the gap in a generation. Health equity through action on the social determinants of health. Geneva: WHO2008 August. 